\title{
Cardiovascular and Respiratory Effects of Medetomidine in Dogs and Influence of Anticholinergics
}

\author{
By Outi Vainio and Liisa Palmu \\ Farmos Group Ltd., Research Center, Turku, Finland.
}

\begin{abstract}
Vainio, O. and L. Palmu: Cardiovascular and respiratory effects of medetomidine in dogs and influence of anticholinergics. Acta vet. scand. 1989, 30, 401-408. A total of 10 laboratory beagles was used to determine the cardiovascular and respiratory effects of medetomidine. The effects of atropine sulphate and glycopyrrolate on heart rate were also observed. Xylazine was included as a positive control. Medetomidine induced initial hypertension followed by a longer lasting hypotensive period. Evident bradycardia with second degree atrioventricular blocks and decrease in respiratory frequency was observed. Atropine sulphate and glycopyrrolate transiently abolished the bradycardic effect of medetomidine. Xylazine exhibited a similar cardiovascular and respiratory pattern to medetomidine.
\end{abstract}

atropine sulphate; glycopyrrolate; blood pressure; heart rate; ECG; respiratory frequency.

\section{Introduction}

Medetomidine (MPV-785), 4-[1-(2,3-dimethylphenyl) ethyl]-1H-imidazole (Fig. 1) is a new sedative and analgesic drug intended for use in dogs and cats (Vainio et al. 1986/87, Vainio et al., 1989). Its cardiovascular properties have been studied in rats (Savola et al. 1986) and human volunteers (Scheinin et al. 1987), hypotension and clear bradycardia being evident in both trials.

The mechanism of the cardiovascular and sedative/analgesic action of medetomidine

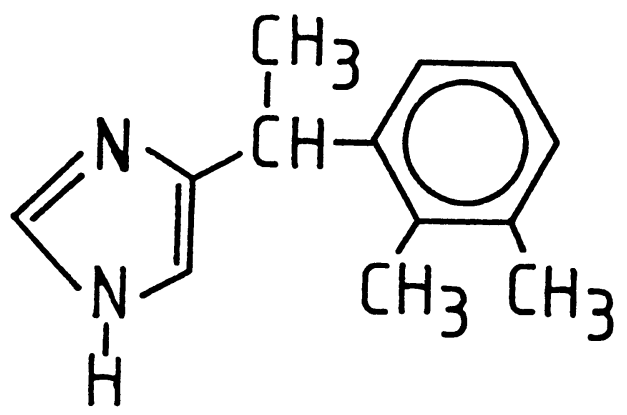

Figure 1. The chemical structure of medetomidine. is most probably alpha-2-adrenoceptor agonism (Virtanen 1985, MacDonald \& Virtanen 1986, Savola et al. 1986, Virtanen et al. 1988). The same mechanism mediates the effects of xylazine (Rompun ${ }^{\circledR}$ ) (Hedler et al. 1981, Hsu 1981) and detomidine (Domosedan $\left.{ }^{8}\right)$ (Vainio 1983, Virtanen \& Nyman 1985). They are both frequently used veterinary sedatives with bradycardic (Hubbell \& Muir 1982, Vainio 1985) and hypotensive (Hubbell \& Muir 1982, Nilsfors \& Kvart 1986, Savola 1986) properties.

The present study was performed to investigate the cardiovascular and respiratory effects of medetomidine in dogs. Xylazine was included as a positive and placebo as a negative control. The effect of atropine and glycopyrrolate on heart rate was also observed.

\section{Materials and methods}

The study was performed in 2 parts. Firstly, effects on the arterial blood pressure, heart rate, electrocardiogram (ECG) and respiratory frequency were observed. Secondly, ef- 
fect of atropine and glycopyrrolate on heart rate was studied.'

Ten laboratory beagles were used, both parts of the study had their own dogs, 3 bitches and 2 males. The ages varied from $0.5 \mathrm{yrs}$ to $1.5 \mathrm{yrs}$ and weights from $9.3 \mathrm{~kg}$ to $14.8 \mathrm{~kg}$ at the beginning of the study. The dogs were conditioned to $12 \mathrm{~h}$ light and $12 \mathrm{~h}$ dark periods. Food and water were available ad libitum.

The following test substances were included. The first part: medetomidine $\mathrm{HCl}$ (Domitor $^{\circledR}$, Farmos Group Ltd) 40, 80 and 160 $\mu \mathrm{g} / \mathrm{kg} \mathrm{BW}$, xylazine $\mathrm{HCl}$ (Rompun ${ }^{\circledR}$, Bayer Leverkusen) $3 \mathrm{mg} / \mathrm{kg} \mathrm{BW}$ and physiological saline. They were sealed in coded vials where the concentrations of the solutions were adjusted to permit a standard dosing volume of $0.1 \mathrm{ml} / \mathrm{kg} \mathrm{BW}$. The second part: medetomidine (Domitor ${ }^{\circledR}$, Farmos Group Ltd) 50 $\mu \mathrm{g} / \mathrm{kg} \mathrm{BW}$, atropine sulphate (Atropin, Orion Pharmaceutical Co.) $30 \mu \mathrm{g} / \mathrm{kg}$ BW and glycopyrrolate (Gastrodyn, Huhtamäki Pharmaceuticals/Medica) $10 \mu \mathrm{g} / \mathrm{kg} \mathrm{BW}$.

The drugs were injected intramuscularly into gluteal muscles and intravenously into $\mathrm{V}$. cephalica antebrachii in the first part of the study (cardiovascular and respiratory effects of medetomidine), both modes of administration were tested independently. In the second part of the study (effect of atropine and glycopyrrolate) only the i.m. route was used. Between the treatments there were at least 4 rest days.

In the first part of the study, the recordings of blood pressure, heart rate and respiratory rate were reported before medetomidine and at $\mathbf{2}$ min intervals during the first half $\mathrm{h}$ and at 5 min intervals during the latter half $h$ post injection. Further measurements were made at $1.25 \mathrm{~h}, 1.5 \mathrm{~h}, 1.75 \mathrm{~h}, 2 \mathrm{~h}, 2.5 \mathrm{~h}, 3 \mathrm{~h}, 3.5 \mathrm{~h}$, $4 \mathrm{~h}, 5 \mathrm{~h}$ and $6 \mathrm{~h}$ after the administration of the drugs. The ECG recordings were made at the same time points for a duration of $1 \mathrm{~min}$.
In the second part of the study atropine/glycopyrrolate were injected $10 \mathrm{~min}$ before medetomidine or concomitantly, medetomidine immediately after atropine/glycopyrrolate. Heart rate was recorded before atropine/glycopyrrolate before medetomidine and thereafter at $5 \mathrm{~min}$ time intervals for $1 \mathrm{~h}$ and at $1.25 \mathrm{~h}, 1.5 \mathrm{~h}, 1.75 \mathrm{~h}, 2 \mathrm{~h}, 3 \mathrm{~h}, 4 \mathrm{~h}$ and $5 \mathrm{~h}$ post medetomidine.

Prior to the experiments, each dog in the first part of the study underwent a surgical procedure to insert a PVC-catheter into the aorta for direct blood pressure measurement (for more details of method, see Herd \& Banger 1964). The tip of the catheter was closed with a plastic cap with a rubber membrane inside (B. Braun Melsung AG, West Germany) and fixed under the loose skin of the dorsal neck. The catheter was kept open by flushing with heparinized physiological sodium chloride (25 I.U. heparin/1 $\mathrm{ml} 0.9 \%$ $\mathrm{NaCl}$ ) at intervals of 2-4 days. A recovery period of at least 2 weeks was allowed before the subsequent experiments.

For blood pressure measurement the membrane of the cap of the arterial catheter was punctured through the skin and connected to a blood pressure meter Olli-532 (Ollituote Oy, SF-02320, Espoo, Finland). For heart rate and ECG recordings, disposable adhesive disc electrodes (Medicotest Q-10-A, Medicotest, Ølstykke, Denmark) were attached to both flanks behind the elbows. Hairs were first shaved from the area and the bare skin wiped with fat solvent to allow better contact. The disk electrodes were connected to Olli-432 monitor (2-channel memory monitor with heart rate meter) and ECG-recorder Olli-296. Respiratory rate meter Olli-333 recorded the respiratory frequency by measuring the impedance changes of the thorax. Therefore another pair of disk electrodes were inserted on both flanks above the earlier ones. 
Both parts of the study exhibited cross over design which utilized $5 \times 5$ Latin square design. The AUC's (area under the curve) for blood pressure, heart rate and respiratory frequency were calculated and thereafter analyzed by an ANOVA model. The minimum and maximum time peaks, and the respective observed peak values were analyzed by using the Friedman's two-way analysis of variance.

\section{Results}

\section{Blood pressure}

Medetomidine and xylazine induced an initial elevation in the mean blood pressure. The increase was higher after iv (26\%) than after im (18\%) administration. The effects of different doses of medetomidine or xylazine did not differ statistically significantly from each other. During the following $1 / 2 h$, the blood pressure returned to the starting

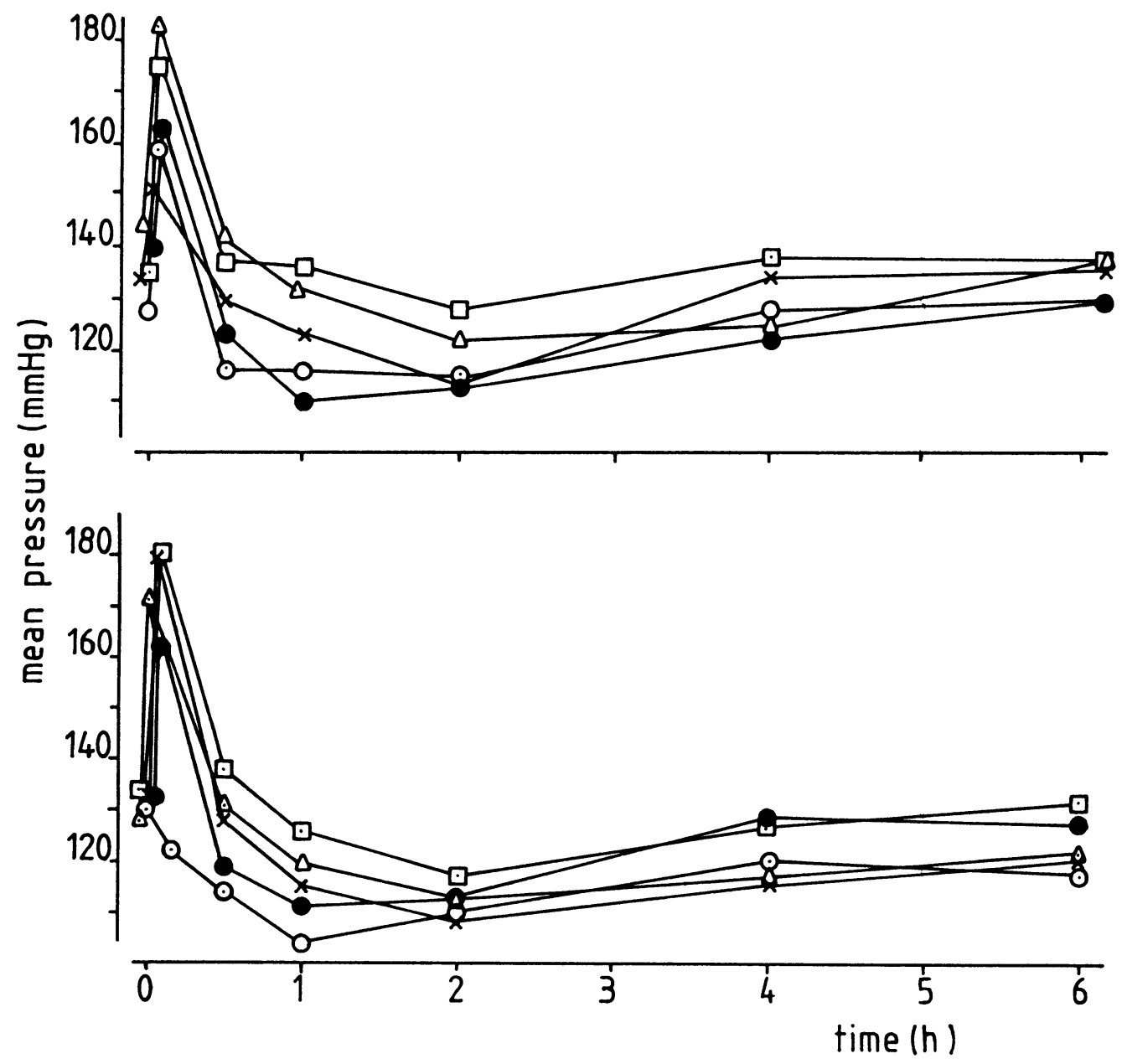

Figure 2. The effect of medetomidine and xylazine on mean arterial blood pressure in dogs. Im (upper panel) and iv (lower panel) routes of injection were used. Values are arithmetic means. $n=5(\times)$ medetomidine 40 $\mu \mathrm{g} / \mathrm{kg},(\triangle)$ medetomidine $80 \mu \mathrm{g} / \mathrm{kg},(\square)$ medetomidine $160 \mu \mathrm{g} / \mathrm{kg}$, (•) xylazine $3 \mathrm{mg} / \mathrm{kg}$ and $(\bigcirc)$ placebo. 
level or was lower than that level. The hypotension was not statistically significant except with the iv route of medetomidine $\mathbf{4 0}$ $\mu \mathrm{g} / \mathrm{kg}$ and xylazine. In the cases of hypotension, blood pressure returned to the initial level in 3-4 h. Details are presented in Fig. 2.

\section{Heart rate and ECG}

An evident decrease of heart rate occurred in 2-4 min after both drugs and both modes of injection. The drop was approximately $63 \%$ from the starting level. The effects of different doses of medetomidine and xylazine did not differ from each other in this respect. After the im route of injection the decrease occured slower than after iv. A quicker reco- very to control values occurred after im xylazine than after im medetomidine doses. After iv administration, both the lowest dose of medetomidine $(40 \mu \mathrm{g} / \mathrm{kg})$ and xylazine returned the heart rate to the initial level sooner than after the higher doses of medetomidine. The difference was statistically significant. For more details, see Fig. 3.

The most prominent changes in ECGrhythm induced by both medetomidine and xylazine were bradycardia and pronounced sinus arrhythmia. Occasional second degree atrioventricular blocks were seen at the doses of 80 and $160 \mu \mathrm{g} / \mathrm{kg}$ of medetomidine. The blocks appeared during the first $15 \mathrm{~min}$ after injection.

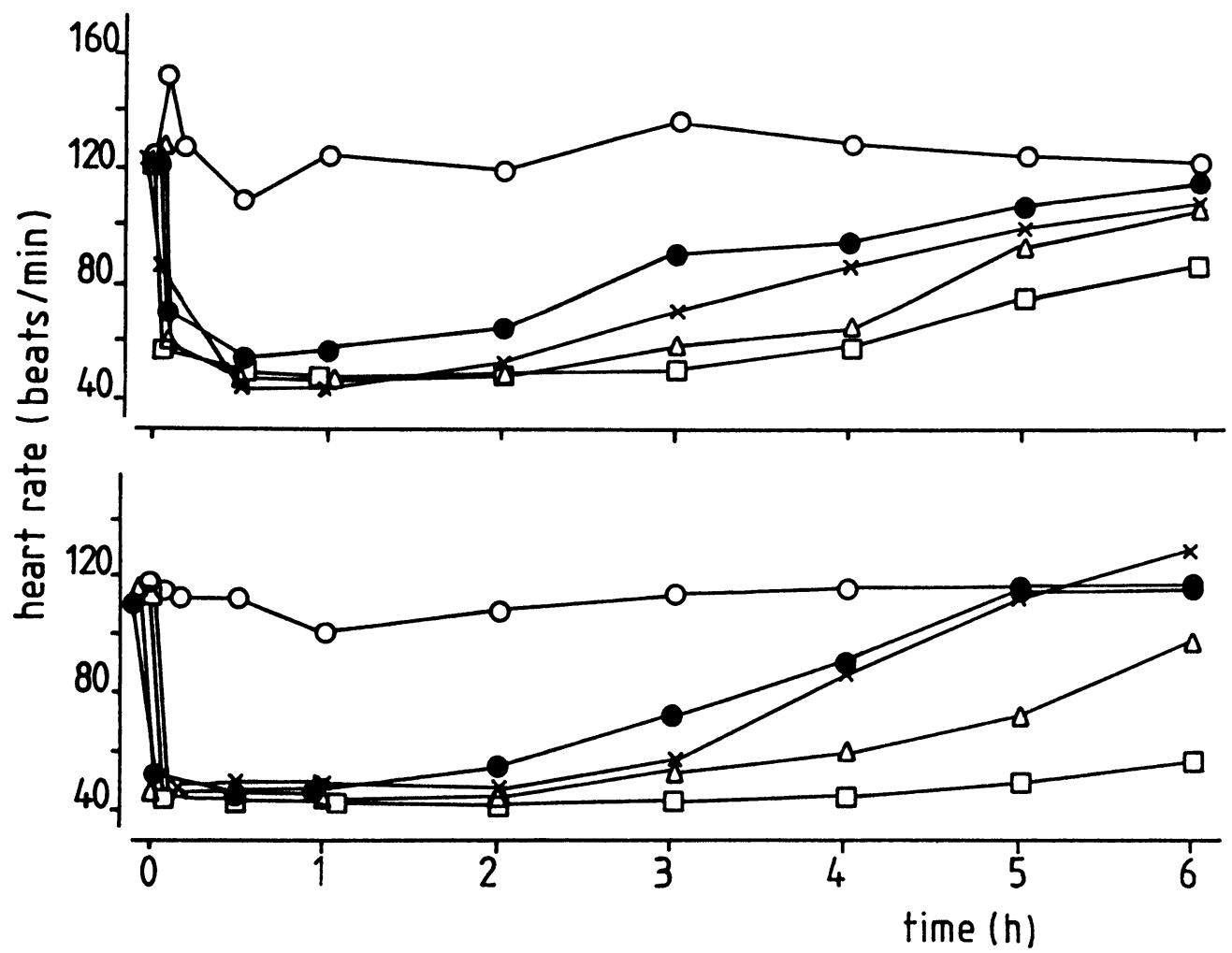

Figure 3. The effect of medetomidine and xylazine on heart rate in dogs. Im (upper panel) and iv (lower panel) routes of injection were used. Values are arithmetic means. $n=5 .(\times)$ medetomidine $40 \mu \mathrm{g} / \mathrm{kg},(\triangle)$ medetomidine $80 \mu \mathrm{g} / \mathrm{kg}$, ( $\square)$ medetomidine $160 \mu \mathrm{g} / \mathrm{kg}$, (•) xylazine $3 \mathrm{mg} / \mathrm{kg}$ and $(\bigcirc)$ placebo. 


\section{Atropine and glycopyrrolate}

Atropine and glycopyrrolate significantly prevented the medetomidine induced bradycardia. However, the effect was not permanent. In cases where atropine or glycopyrrolate were injected $10 \mathrm{~min}$ before medetomidine, the post medetomidine heart rate stayed at starting level for 20-30 min before the decrease. Concomitant administration of medetomidine and the anticholinergic agent, induced a rapid drop of heart rate followed by a tachycardic period lasting approximately $1 \mathrm{~h}$. Evident bradycardia developed thereafter. Recovery to the control values occurred in 4-5 $\mathrm{h}$ post medetomidine injection. Atropine or glycopyrrolate medication did not effect the speed of recovery. The effects of atropine and glycopyrrolate did not differ from each other. See Fig. 4. for more detailed information.

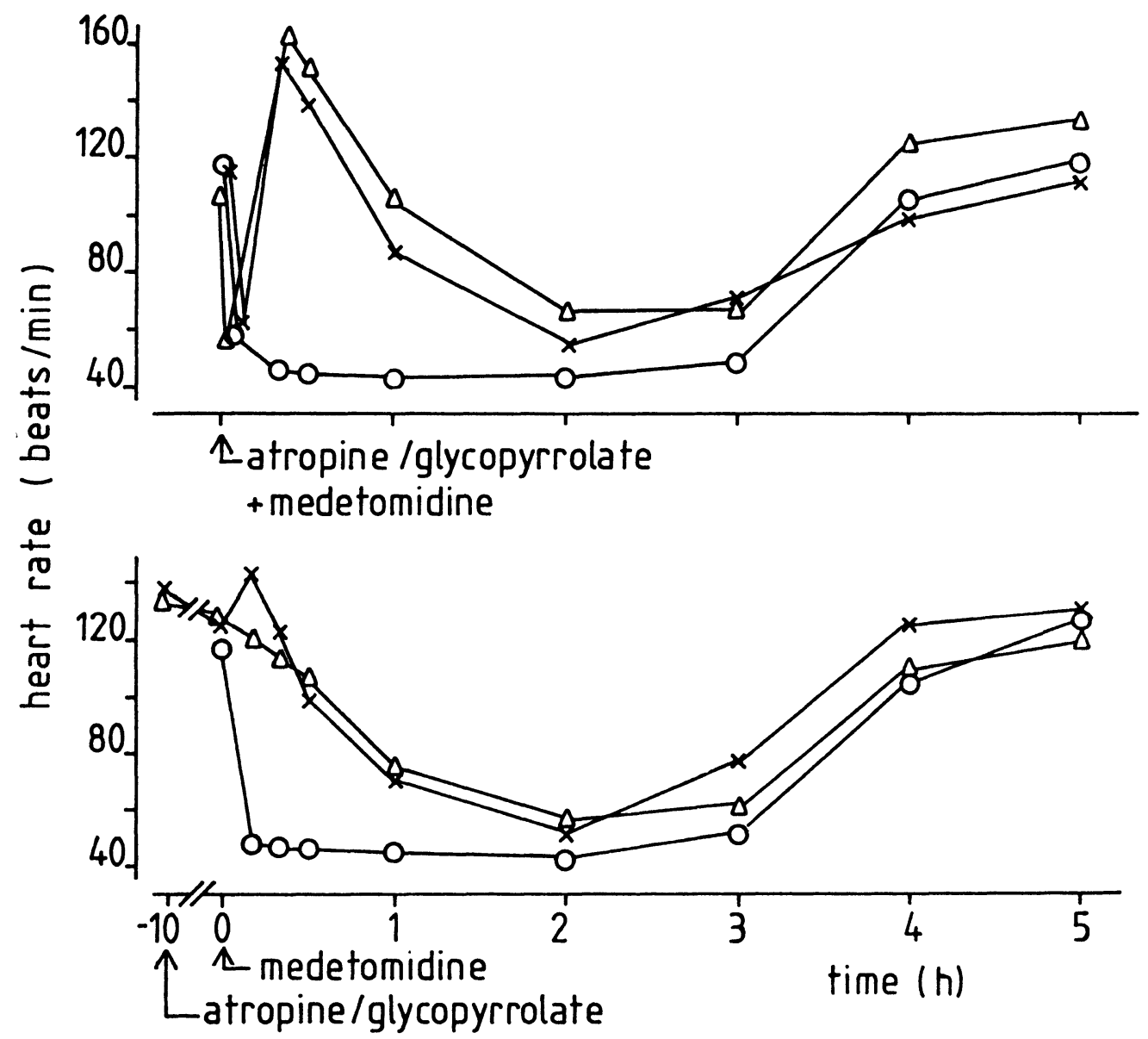

Figure 4. The effect of im atropine sulphate and glycopyrrolate on heart rate after im medetomidine of 50 $\mu \mathrm{g} / \mathrm{kg}$ in dogs. Medetomidine and the anticholinergics were injected concomitantly (upper panel) or the anticholinergics 10 min before medetomidine (lower panel). Values are arithmetic means. $n=5 .(x)$ atropine sulphate $30 \mu \mathrm{g} / \mathrm{kg}+$ medetomidine $50 \mu \mathrm{g} / \mathrm{kg},(\triangle)$ glycopyrrolate $10 \mu \mathrm{g} / \mathrm{kg}+$ medetomidine $50 \mu \mathrm{g} / \mathrm{kg},(\bigcirc)$ medetomidine $50 \mu \mathrm{g} / \mathrm{kg}$. 


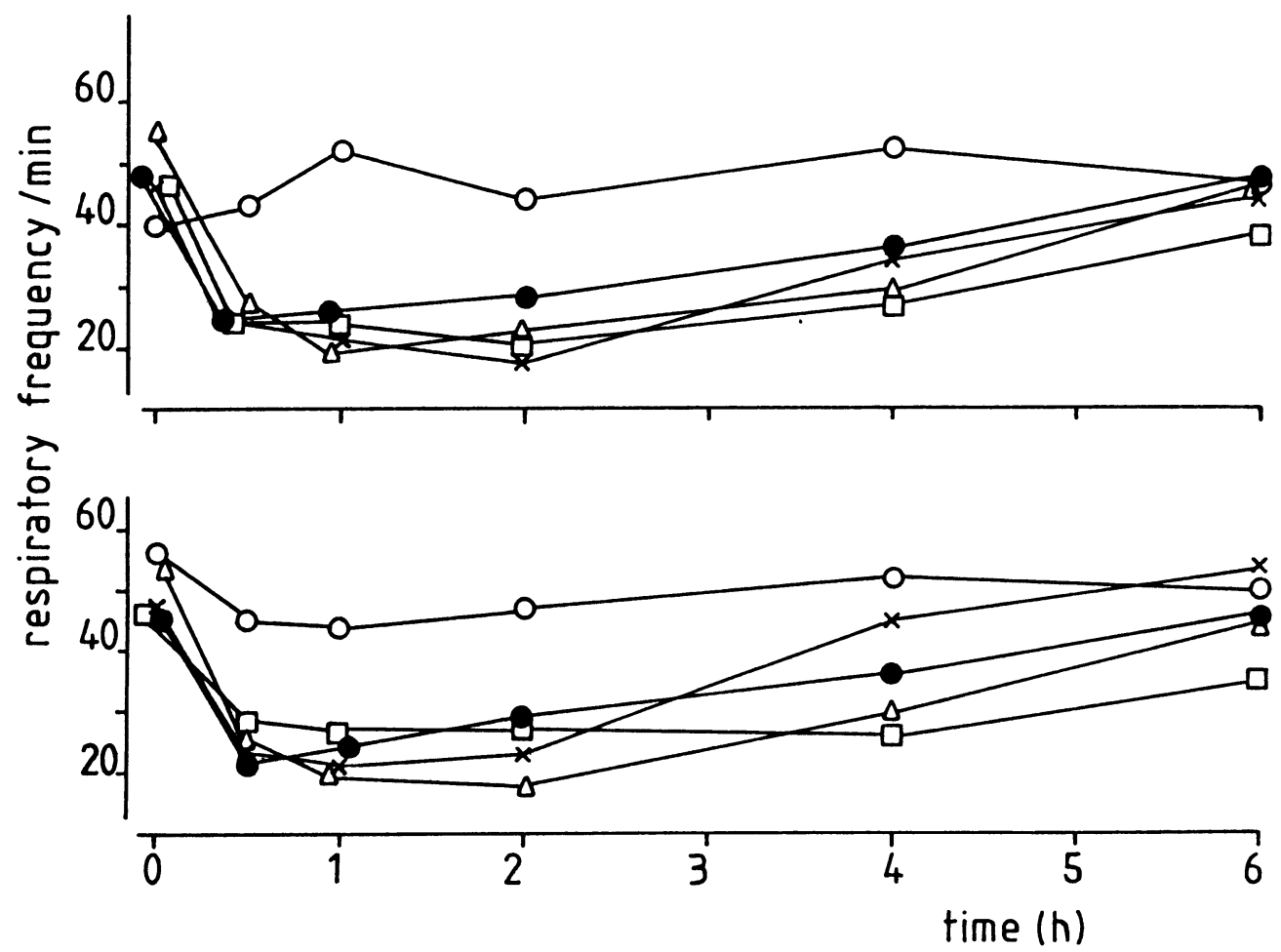

Figure 5. The effects of medetomidine and xylazine on respiratory rate in dogs. Im (upper panel) and iv (lower panel) routes of injection were used. Values are arithmetic means. $\mathrm{n}=5$. ( $\times$ ) medetomidine $40 \mu \mathrm{g} / \mathrm{kg},(\triangle) \mathrm{med}$ etomidine $80 \mu \mathrm{g} / \mathrm{kg},(\square)$ medetomidine $160 \mu \mathrm{g} / \mathrm{kg},(\bullet)$ xylazine $3 \mathrm{mg} / \mathrm{kg}$ and $(\bigcirc)$ placebo.

\section{Respiratory rate}

After both drugs and both modes of injection respiratory rate showed a clear decrease. The lowest rates were $18-25$ breaths/min. Thereafter a gradual return occurred to the control level. The effects of the different doses of medetomidine and xylazine did not statistically differ from each other. Details are collected in Fig. 5.

\section{Discussion}

The medetomidine doses used in this study were chosen on the following basis: 40 $\mu \mathrm{g} / \mathrm{kg}$, normal clinical dose; $80 \mu \mathrm{g} / \mathrm{kg}$, high dose and $160 \mu \mathrm{g} / \mathrm{kg}$, overdose. Xylazine was administered at the highest dose level recommended by the manufacturer $(3 \mathrm{mg} / \mathrm{kg})$.
An initial elevation of blood pressure followed by hypotension was observed after im and iv injections of medetomidine and xylazine. Similar results for the effect of xylazine in dogs have been reported by other investigators (Klide et al. 1975, Steiner 1980, Hsu \& Hembrough 1985). Intramuscularly administered placebo had a parallel effect indicating that it is the consequence of an unpleasant event.

The initial vasopressor effect on medetomidine is thought to be mediated through a direct effect on the post synaptically located alpha-2-adrenoceptors in the smooth muscle of resistance vessels (Savola et al. 1986). The fall in blood pressure after medetomidine probably results from stimulation of central 
alpha-2-adrenoceptors (Savola et al. 1986). The effects of xylazine on blood pressure are attributed to the same mechanism of action (involvement of peripheral and central alpha-2-adrenoceptors) (Campbell et al. 1979, Doxey et al. 1981).

Medetomidine and xylazine induced profound bradycardia and sinus arrhythmia. Our results with xylazine confirm the previous findings made in dogs after xylazine treatment (Klide et al. 1975, Hubbel \& Muir 1982, Hsu \& Hembrough 1985). The bradycardic effect of xylazine has been proposed to be due to increased vagal tone, diminished activity of the cardiac sympathetic nerves (Klide et al. 1975) or a direct depressive effect on the myocardium (Aziz \& Carlyle 1978). The cardiodepressive effects of alpha2 agonists, including xylazine (and detomidine), are apparently mediated via central alpha-2 adrenoreceptors. Savola et a!. (1986) reported that the bradycardic effect of medetomidine was probably of central origin.

In the present work the anticholinergic drugs, atropine and glycopyrrolate, transiently prevented the decrease in heart rate after medetomidine injection suggesting that increased vagal tone would participate to the drop in heart rate.

After simultaneous administration of atropine and medetomidine there was found a rapid fall in heart rate, due to the rapid penetration of medetomidine into the brain and its effect to increase vagal activity (either directly or indirectly as a result of the increase in blood pressure). Atropine absorbed slowlier and the anticholinergic effect was seen later as a clear elevation in the heart rate. When given 10 min before medetomidine, atropine itself had virtually no effect on heart rate but it delayed the onset of medetomidine induced bradycardia. This delayed bradycardic effect of medetomidine could be due to a decrease in noradrenaline relea- se, either at peripheral alpha-2 adrenoceptors in the heart, or via an inhibition of central sympathetic tone.

Respiratory depression was evident with both drugs. However, even the lowest rates of respiration were within the normal limits for resting dogs (Park et al. 1970).

In conclusion, medetomidine $\mathrm{HCl}$ proved to have cardiovascular and respiratory depressing properties in laboratory beagles. The bradycardic effect could be abolished with atropine sulphate and glycopyrrolate premedication. However, the inhibitory effects of the anticholinergics was not permanent. The positive control drug, xylazine, exhibited a comparable cardiovascular and respiratory pattern as medetomidine.

\section{Acknowledgements}

The authors are grateful to Assoc. Prof. Pekka Laippala for his statistical advise and to Mrs. Paivi Kontınpaa and Mrs. Merja Ojala for their skilful technical assistance.

\section{References}

Azız MA, Carlyle SS: Cardiovascular and respiratory effects of xylazine in sheep. Zbl. Vet. Med. A 1978, 25, 173-180.

Campbell KB, Klavano PA, Rıchardson P, Alexander $J E$ : Hemodynamic effects of xylazıne in the calf. Amer. J. Vet. Res. 1979, 40, 1777-1780.

Hedler L, Stamm G, Weitzell R, Starke K: Functional characterizations of central alpha-adrenoceptors by yohimbıne diastereomers. Eur. J. Pharmacol. 1981, 70, 43-52.

Herd JA, Banger AC: Simplified technique for chronic cathetrization of blood vessels. J. Appl. Physiol. 1964, 19, 791-792.

Hsu WH: Xylazine-induced depression and its antagonism by alpha-adrenergic blocking agents. J. Pharmacol. Exp. Ther. 1981, 218, 188-212.

Hsu WH, Lu Z-X, Hembrough FB: Effects of xylazine on heart rate and arterial blood pressure in conscious dogs, as influenced by atropine, 4-aminopyridine, doxapram and yohimbine. J. Amer. Vet. Med. Assoc. 1985, 186, 153-156. 
Hubbell JAE, Muir WW: Effect of xylazine hydrochloride on canine splenic weight: An index of vascular capacity. Amer. J. Vet. Res. 1982, 43, 2188-2192.

Klide AM, Calderwood HW, Soma LR: Cardiopulmonary effects of xylazine in dogs. Amer. J. Vet. Res. 1975, 36, 931-935.

MacDonald E, Virtanen R: Medetomidine, a new veterinary sedative: mode of action and therapeutic implications. Proceedings. 29th annual meeting of the Canadian Federation of Biological Societies, Guelph, 1986, p. 174.

Nilsfors $L, K$ vart $C$ : Preliminary report on the cardiorespiratory effects on the antagonist to detomidine MPV-1248. Acta vet. scand. 1986, Suppl. 82, 121-129.

Park JF, Clarke WJ, Bair WJ: Respiratory system. In: The Beagle as an Experimental Dog. Ed. by AC Andersen, 1st ed., Iowa State University Press, Ames, Iowa, 1970, p. 292.

Savola J-M: Cardiovascular actions of detomidine. Acta vet. scand. 1986, Suppl. 82, 47-57.

Savola J-M, Ruskoaho H, Puurunen J, Salonen JS, Karkı NT: Evidence for medetomidine as a selective and potent agonist of $\alpha_{2}$-adrenoceptors. J. Auton. Pharmacol. 1986, 5, 275-284.

Scheınin M, Kallo A, Koulu M, Vilkarı J, Scheınin $H$ : Sedative and cardiovascular effects of medetomidine, a novel selective $\alpha_{2}$-adrenoceptor agonist, in healthy volunteers. Brit. J. Clin. Pharmacol. 1987, 24, 443-451.

Steiner S: Untersuchungen uber den Wirkungsmechanismus des Xylazin (Rompun ${ }^{\circledR}$ ). [Studies of the mechanism of action of xylazine (Rompun $\left.{ }^{\circledR}\right)$.] Inaugural Dissertation, Freie Universitat Berlin, Berlin 1980.

Vainıo $O$ : Detomidine hydrochloride. A novel imidazole type sedative analgesic. In: Veterinary Pharmacology and Toxicology. Eds. Y. Ruckebusch, P-L Toutain, and GD Goritz, MTP Press Ltd, Boston 1983, pp. 798-799.
Vainıo O: Detomidine, a new sedative and analgesic drug for veterinary use. Academic dissertation, College of Veterinary Medicine, Helsinki, Finland 1985.

Vainıo O, Palmu L, Virtanen R, Wecksell J: Medetomidine, a new sedative and analgesic drug for dogs and cats. J. Assoc. Vet. Anaesth. 1986/87, 14, 53-55.

Valnio $O$, Vaha-Vahe T, Palmu L: Sedative and analgetic effect of medetomidine in dogs. J. Vet. Pharmacol. Therap, 1989, 12, 225-231.

Virtanen $R$ : Detomidine and MPV-785, two sedative/analgesic imidazole derivatives with different species selectivity. Abstr. 3rd Congress of the European Association for Veterinary Pharmacology and Toxicology, Ghent, 1985, p. 39.

Virtanen $R$, Nyman $L$ : Evaluation of $\alpha_{1}$-and $\alpha_{2}$-adrenoceptor effects of detomidine, a novel veterinary sedative analgesic. Eur. J. Pharmacol. 1985, 108, 163-169.

Virtanen $R$, Savola J-M, Saano V, Nyman L: Characterization of the selectivity, specificity and potency of medetomidine as an $\alpha_{2}$-adrenoceptor agonist. Eur. J. Pharmacol. 1988, 150, 9-14.

\begin{abstract}
Sammanfattning
Kardlovaskulara och respiratoriska effekter av medetomıdin ı hundar och inverkan av antıkolınergıska amnen.

De kardiopulmonara effekterna av medetomidin studerades med intramuskular och intravenos applicering. Effekten av atropinsulfat och glykopyrrolat på hjartfrekvensen iakttogs också. Xylazin fungerade som positiv kontroll.

Medetomidin hojde forst blodtrycket och darefter foljde en langre hypotensiv period: bradykardin med $2^{\circ}$ atrioventrikular block intraffade. Sankning i andningsfrekvensen observerades. Atropinsulfat och glykopyrrolat motverkade bradykardin, men effekten var inte permanent. Xylazins farmakologiska profil var liknande som medetomidinets.
\end{abstract}

(Accepted January 9, 1989).

Reprints may be requested from: Outi Vainio, Farmos Group Ltd., P. O. Box 425, SF-20101 Turku, Finland. 